\title{
A experiência do exílio na obra de Inácio Rebelo de Andrade
}

\section{The experience of exile in Inácio Rebelo de Andrade's work}

Zuleide Duarte [zuleide.duarte@hotmail.com]

Universidade Estadual da Paraíba (UEPB), Brasil

\begin{abstract}
RESUMO:
O tópico da emigração perpassa as literaturas de países que sofreram o processo de colonização desde o seu nascedouro, e chega à contemporaneidade pelas múltiplas vozes dos escritores disseminados pelo mundo. Inácio Rebêlo de Andrade, poeta e ficcionista angolano radicado em Portugal, filia-se a essa tradição, realizando uma obra que tematiza o binômio emigrante-exilado, criando personagens que são vítimas da saudade e da obsessão pelo retorno à pátria. Utilizando subsídios dos estudos pós-coloniais, rastreamos a representação do estranhamento ocasionado pelo exílio no romance Na babugem do êxodo (2005), enfocando o exercício de evocação da terra natal através da escrita, onde o elemento histórico e referencial do exílio incorpora-se ao universo representativo, conformando-o e modificando-o. Evidentemente, há muito mais que a questão da língua no tocante à emigração. $\mathrm{O}$ indivíduo abandona suas mais arraigadas referências e lança-se no desconhecido, cuja estranheza se apresenta em primeiro plano na dificuldade com uma nova língua. No caso dos emigrados africanos para os países de língua portuguesa, o problema é aparentemente menor por causa da língua comum; entretanto, as diferenças acentuadas entre as duas formas de falar o português estabelecem o desconforto característico de quem chega ao estrangeiro. Assim, torna-se imperiosa a necessidade de "alfabetizar-se" (na própria língua) para sobreviver. Desenraizar-se para suplantar a dor da perda. É curioso observar que, ao lado do secreto desejo de retornar à aldeia, todo emigrante alimentou antes o atávico sonho de procurar outras paragens. No exílio, a saudade, aumentada pela sensação de forasteiro, faz com que aquele ponto além-mar se transforme no referencial mais legítimo de sua existência.
\end{abstract}

\section{Palavras-chave:}

Pós-colonial; emigração, saudade, lusofonia

\begin{abstract}
:
The emigration topics permeate the literatures from countries that have suffered the colonization process since its birth, and gets to contemporaneity through the multiple voices of the writers disseminated through the world. Inácio Rebêlo de Andrade, Angolan poet and fiction writer settled in Portugal, joins this tradition, doing a work that thematizes the binomial emigrant-exiled, creating roles that are victims of home country missing and return obsession. Using post-colonial studies' subsides, we track the estrangement representation caused by the exile on the novel $\mathrm{Na}$ babugem do exxodo (2005), focusing on the exercise of home country evoking through the written language, where the historical and referential exile element incorporate the representative universe, conforming and changing it. Evidently, there is much more than the language itself when it comes to emigration. The individual abandons his most deep
\end{abstract}


references and jumps into the unknown, where the strangeness first appears as his difficulty with the new language. In the African emigrates to the Portuguese countries language, the problem is apparently not that big because of the common language, although the accentuated differences between the two ways of speaking Portuguese establish the peculiar lack of comfort of who arrives in a new land. So, it is made imperative the need to get "alphabetized" (in his own language) to survive, to let go your roots to outcome the pain of the loss. It is interesting to observe that all emigrants have fed the dream of searching for a new place to live before he starts dreaming to go back to his or her village. In the exile, the missing of his homeland, made bigger by the feeling of being a foreigner, makes that overseas place a most legitimate reference of his existence.

\section{KEYWORDS:}

Post-colonial; emmigration; missing; lusophony

RECEBIDO 2015-8-20; ACEITE 2016-1-30

Não é verdade que as visões do exílio na literatura e na religião obscurecem o que é realmente horrível? Que o exílio é irremediavelmente secular e insuportavelmente histórico, que é produzido por seres humanos para outros seres humanos e que, tal como a morte, mas sem sua última misericórdia, arrancou milhões de pessoas do sustento da tradição, da família, da geografia?

(Said 2001: 47)

O tópico da emigração perpassa as literaturas de países que sofreram o processo de colonização desde o seu nascedouro, e chega à contemporaneidade pelas múltiplas vozes dos escritores disseminados pelo mundo. Inácio Rebelo de Andrade, poeta e ficcionista angolano radicado em Portugal, filia-se a essa tradição, realizando uma obra que tematiza o binômio emigranteexilado, criando personagens que são vítimas da saudade e da obsessão pelo retorno à pátria. Utilizando subsídios dos estudos pós-coloniais, rastreamos a representação do estranhamento ocasionado pelo exílio no romance $\mathrm{Na}$ babugem do êxodo (2005), enfocando o exercício de evocação da terra natal através da escrita, onde o elemento histórico e referencial do exílio incorpora-se ao universo representativo, conformando-o e modificando-o. Evidentemente, há muito mais que a questão da língua no tocante à emigração. O indivíduo abandona suas mais arraigadas referências e lança-se no desconhecido, cuja estranheza se apresenta em primeiro plano na dificuldade com uma nova língua. No caso dos emigrados africanos para os países de língua portuguesa, o problema é aparentemente menor por causa da língua comum; entretanto, as diferenças acentuadas entre as duas formas de falar o português estabelecem o desconforto característico de quem chega ao estrangeiro. Assim, torna-se imperiosa a necessidade de "alfabetizar-se" (na própria língua) para sobreviver. Desenraizar-se para suplantar a dor da perda. É curioso observar que, ao lado do secreto desejo de retornar à aldeia, todo emigrante 
alimentou antes o atávico sonho de procurar outras paragens. No exílio, a saudade aumentada pela sensação de forasteiro, faz com que aquele ponto além-mar se transforme no referencial mais legítimo de sua existência.

Discutimos aqui o livro de Inácio Rebelo de Andrade, escritor angolano que vive em Portugal, alimentando o sentimento de desterro e estranhamento, sofrimento que tenta purgar através da escrita. Segundo Stéfhane Mosès (1982: 186),

o exílio não significa somente e talvez nem mesmo fundamentalmente, o distanciamento geográfico em relação ao país (lugar) de origem; o exílio é a separação ela própria, isto é um apartarse em relação ao mundo e à sua história.

O escritor Colin Wilson também destaca a condição do exilado, ressaltando que, para além das fronteiras geográficas (hoje tão lábeis), o apartamento ou a separação opera-se no interior do indivíduo, ocasionando um vazio que nem o retorno é capaz de remediar. Wilson nomeia esse estrangeiro de outsider, analisando casos paradigmáticos como Merseault, personagem de O Estrangeiro (1942) do autor argelino Albert Camus, ele mesmo um exilado no sentido amplo da acepção que utilizamos aqui. Wilson ainda se estende apontando outros como Des Esseintes, personagem de $\grave{A}$ Rebours de Joris Huysmans, figura que na sua excentricidade revela-se um exilado em meio à multidão.

Interessa observar que o exílio deixou de evocar aquela imagem famosa de "Napoleão em Elba" ou ainda, da fuga dos judeus do Egito. Uma visão atualizada leva a formular a compreensão do fato sem, entretanto, torná-lo menos penoso. Interiorizado, vivido como sensação de galho arrancado ao tronco, o sentimento do exílio hospeda-se, também, na alma de quem nunca saiu da sua terra mas, paradoxalmente, nunca esteve ali por inteiro. Deste tipo de exílio sofre o homem contemporâneo, distante de tudo e de todos, incapaz de sentir confortável na própria pele. São semelhantes ao kafkiano Gregor Samsa (A Metamorfose) espalhados pela vida.

A criação literária expõe muito bem essa questão. A literatura do exílio ou da emigração constitui um dos filões mais interessantes de análise pois o que é a literatura atual senão um imenso caleidoscópio de múltiplas, infindáveis cores e dicções? Ao emigrar, primeiramente, da pátria, dos familiares, dos amigos e, em seguida, da própria língua, o autor contemporâneo exila-se na Babel do multiculturalismo, onde sua inserção no mundo das letras e, por extensão, no mundo da cultura, faz-se ao lado de milhares de outros debutantes locais e emigrados, permitindo a formação de uma república particular, onde a auto-expressão é a regra. O personagem outsider analisado por Colin Wilson é um fora de lugar, um deslocado ou, em situações mais radicais, um rejeitado. Segundo ele, o outsider não tem certeza de quem ele é. Ele encontrou um eu, mas esse não é o seu verdadeiro eu. Sua maior preocupação é a de encontrar o caminho de volta. E esse caminho passa necessariamente pela linguagem; escreve-se para inscrever-se de maneira irrefutável na lembrança daqueles que são nossos contemporâneos; escreve-se para não se cair no esquecimento e para se fugir da solidão. A literatura (ou a linguagem) é a tábua de salvação contra a marginalização do indivíduo, seja ele ficcional ou real. Analisando a posição ocupada por autores como Kafka (1883-1924), James Joyce (1882 -1941) e Samuel Beckett (1906 — 1989) em relação às suas culturas de origem e à maneira como eles utilizam a linguagem (por movimentos centrípetos de territorialização e desterritorialização), Gilles Deleuze afirma: 
Quantas pessoas hoje vivem em uma língua que não é a delas? Ou então nem mesmo conhecem mais a delas, ou ainda não a conhecem, e conhecem mal a língua maior da qual são obrigadas a se servir? Problema dos imigrados, e sobretudo de seus filhos. Problema das minorias. Problemas de uma literatura menor, capaz de escavar a linguagem e de fazê-la seguir por uma linha revolucionária sóbria? Como tornar-se o nómade e o imigrado e o cigano de sua própria língua? Kafka diz: roubar a criança no berço, dançar na corda bamba.

O indivíduo abandona suas mais arraigadas referências e lança-se no desconhecido, cuja estranheza se apresenta em primeiro plano na dificuldade com uma nova língua. Mesmo sendo, oficialmente a mesma, o estranhamento se instala, mostrando que não se fala, de fato, uma mesma língua. Usa-se o sistema, simplesmente. Assim, Sebastião, órfão português, personagem do livro Na babugem do êxodo, do escritor angolano Rebelo de Andrade, é desterrado para Angola em 1938, em busca de um futuro melhor. Assustado, o rapazinho,

Desde que embarcara em Lisboa, debatia-se entre dois sentimentos aparentemente inconciliáveis: o medo pelo desconhecido e a curiosidade pela descoberta. Quando falavam de África as pessoas referiam animais ferozes, insectos chupadores de sangue, doenças difíceis de tratar... (p. 65).

Na companhia de um amigo do tio Felisberto, Sebastião não tinha outro caminho, já que Maria do Patrocínio, mulher do seu tio, considerava-o dispendioso demais. Enviá-lo para a então colônia portuguesa aliviava a bolsa da família e a responsabilidade pelo futuro do rapaz. Dessa maneira, Sebastião exila-se de sua terra natal para adotar uma nova pátria, Angola, que aprendeu a amar e defender. Aprendendo hábitos e costumes e adaptando a língua, Sebastião fez bom uso do talento que lhe foi confiado. Progrediu financeiramente e, principalmente, angolanizou-se.

A grande provação apresentou-se para ele quando o movimento pela libertação tomou corpo e os portugueses ali radicados passaram a enviar recursos para Portugal, atitude que Sebastião rejeitava pois considerava-se africano: "Esta terra é nossa. É cá que temos de investir o muito ou o pouco que ganhámos" (p.184).

Sebastião, como tantos outros portugueses, não admitia sequer a hipótese de retornar a Portugal. Diferentemente da maioria dos textos estudados, lemos neste romance a experiência do exílio sofrida pelo africano que deseja voltar à terra, à mãe-África. Este, entretanto, não quer voltar para Portuga, onde nasceu, porque considerava-se angolano. Qualquer sugestão de retorno é rejeitada, como abaixo:

Ele lá admitia a hipótese de um dia ter de embalar as biquatas, deixar para trás o resultado de tanto trabalho, entrar num barco ou num avião e regressar a Lisboa. Nunca! O sogro tinha carradas de razão. Corrido dali? Assim, sem mais nem menos? Era bom, era... Só de facto morto! (p. 184).

Sebastião, como o sogro, tinham bens em África que não queriam perder. Mas não era só o apego ao patrimônio que impedia muitos portugueses de regressar. Era também a afeição pela nova pátria. 
Até aqueles que não tinham bens para acautelar rejeitavam a ideia de regressar à aldeia ou à vila onde haviam vivido antigamente. Faziam coro, eram menos radicais, mas não queriam partir:

- Ir embora? Espero e peço a Deus que não.

Com o fim de testemunhar publicamente essa vontade colectiva de ficar, foi convocada uma manifestação junto do Palácio do Governo, onde os oradores do costume declararam alto e bom som que ninguém iria arredar pé dali, muito menos fugir com um candimba do mato. (p.245).

O sistema de colonização também teve suas vítimas brancas. Nem todo português que ia para as antigas colônias possuía bons postos e condições. O livro O filho da preta, de Quirimbo 70, aborda a o problema do branco que devia ao contratador e era menosprezado e desrespeitado tanto pelo colonizadores quantos pelo naturais da terra que percebiam a subalternização a que eram sujeitos aqueles brancos pobres. Eram portugueses que sabiam não serem bem recebidos na antiga metrópole. Portugal não tinha lugar para eles, retornados. Seria um novo êxodo, para um sítio indesejado, estranho. Distanciados de Portugal e sem planos de voltar, esses exilados já não guardavam a memória da terra madrasta nem alimentavam o desejo de regresso.

Paradoxalmente, o mito do eterno retorno transforma-se em angústia e aversão, medo do descaso e de uma pobreza maior, agudizados pelo frio. O retornado só é bem vindo quando regressa cheio de dinheiro como acontecia com figura do "brasileiro", tão bem descrita pelo romancista Camilo Castelo Branco. Esse português apatacado comprava propriedades, títulos e até contraía nobres alianças. A esse tipo acorria toda parentela com bajulações e amavios.

Porém, o homem expulso por contingências alheias a sua vontade, retornando em situação desfavorável representaria um peso para a família e um ônus para o Estado. Ressalvam-se, evidentemente, casos de famílias que não abandonaram os seus e os acolheram e ainda acolhem. Esses não alimentam esta narrativa.

Quando o exílio ocorre por absoluta impossibilidade de permanência no país de origem, convulsionado por acontecimentos sangrentos, como o caso de Angola, gerando uma situação em que não há a menor garantia de sobrevivência, a partida reveste-se de uma tragicidade que só a obra literária, bem como outras expressões artísticas, torna a narratividade possível. A necessidade premente de narrar insinua-se nos interstícios do discurso e acaba por assumir o papel principal, no teatro em que se transformou a existência provisória do exilado. Impedido de retornar, bem como de falar, pois é a palavra, na sua capacidade denunciadora dos fatos, a primeira a ser interditada, o escritor exilado vive a culpa de não poder ficar e de partir partindo-se. "Corpo que é escravo, vai. Alma que é forra, fica," como bem cita Baltasar Lopes na epígrafe de Chiquinho.

Do exílio incontornável para muitos angolanos disse o saudoso poeta David Mestre na apresentação do livro Quando o Huambo era Nova Lisboa (1998):

Nada restou de pé, eu próprio assisti na televisão de Luanda ao pânico da população civil fugindo pelas ruas e tombando sob a metralha com os parcos haveres à cabeça, mulheres e crianças correndo para lado nenhum, para o capim, para o mato, grávidas parindo no caminho, gente desfalecendo à míngua, à sede, à morte anunciada pelo voo paciente e circular dos abutres. 
Este quadro dos acontecimentos que arrasaram o Huambo, no depoimento do poeta angolano, também vítima da polícia política portuguesa PIDE e da guerra colonial com seus efeitos, foi vivido pelo escritor Inácio Rebelo de Andrade, cujo drama o mesmo autor de Subscrito a Giz, David Mestre, assim resume:

Inácio Rebelo de Andrade, um branco nato de Nova Lisboa, parceiro de eleição de Ernesto Lara Filho, com quem compartilhou, nos anos cinquenta e sessenta, uma fase de "profunda inquietação literária e anticolonialista, fundando ambos a efémera Colecção Bailundo" que reivindicava o justíssimo desejo de dar a conhecer os valores do centro, da maior possessão de Portugal em África, acabaria - na deriva dos acontecimentos bélicos que rodearam a independência - por se expatriar, circunstância que implica um pesado ônus em dívida para com o resto da existência (1998: 15-16).

Inácio Rebelo de Andrade tem vários títulos publicados dentre os quais destacam-se Saudades do Huambo (1994, 0 sabor doce das nêsperas amargas (1997), Quando o Huambo era Nova Lisboa (1998), Mãe Loba (2001), Revisitações no exilio (2001), Passageiro sem bilhete (2003), Na babugem do êxodo (2005), A mulata do engenheiro (2007), O pecado maior de Abel (2009), títulos que revelam, de saída, o tema recorrente em sua obra: a pátria de onde partiu, mas da qual jamais logrou esquecer-se ou afastar-se. Nas palavras prévias do livro O pecado Maior de Abel, explica:

Este livro é sobre o drama de alguém que é levado do local onde nasceu para muito longe, deixando atrás de si um passado cheio de afetos. É sobre quem vai viver para outro lugar, onde encontra coisas, gentes e valores até aí desconhecidos - e que se não vê então na contingência de não saber ao certo qual é o seu preço.

Observa-se, nesse depoimento, que o autor teve um exílio forçado, como o Sebastião de $\mathrm{Na}$ Babugem..., e esse fato reflete-se na obra do romancista angolano, cuja saída da terra natal, provocada pela insegurança em uma Angola tomada pela guerra, aconteceu não por decisão pessoal, mas pela imperativa necessidade de proteger a família e preservar-se também por ela. Essa saída, provocada por um conjunto de fatores, inviabilizava, à partida, a permanência e o retorno ao país. Não foi um exílio decretado pelo sistema, como punição por uma falta. Foi, no doloroso sentido de banimento, a expulsão ou a perda do lugar na pátria. A terra, as condições precárias de sobrevivência e a necessidade de conquistar melhores oportunidades para a família apontaram a saída como solução: migrar ou melhor dizendo, fugir para, contraditoriamente, conquistar um dia o direito de voltar e permanecer na pátria. Trata-se de um exílio de ordem geográfica que teve ressonância no psiquismo, uma vez que o sujeito, ao se deslocar fisicamente, sentiu-se excluído do meio em que vivia. Um sentimento de culpa e de abandono passou a dominar esses seres diaspóricos, fugidos da luta que levou muitos à morte. A urgência em reorientar a existência que sobrou, único património levado da pátria, além de um benguelinha, pássaro clandestino que a matreirice das crianças introduziu no outro pássaro, o de ferro, do exílio, configura-se como a única saída face ao desconhecido. A saga do exílio é narrada de maneira contundente no romance $O$ passageiro sem bilhete, obra ditada pela saudade, alimento do exilado, tema e motivo de uma memória que teima em não sair do seu chão, livre 
que é. A esperança alojava-se na alma do exilado que ponderava: "Talvez dois ou três meses, talvez até mais, até os Movimentos se estenderem entre si e a paz regressar de novo. É preciso compreender, ter paciência e esperar" (Passageiro sem bilhete, p. 21).

Os textos prodigalizam informações sobre o clima, a vegetação, a cultura angolana em geral. Na babugem do êxodo está o relato e o comentário da guerra pela independência e da própria libertação do povo. O livro também traz uma cronologia dos fatos importantes ocorridos na cidade do Huambo, antiga Nova Lisboa. A escrita funciona como um imenso painel descortinado para o leitor que penetra a paisagem angolana,

Em fevereiro Luanda é um forno. Do céu limpo de nuvens, o sol solta o seu calor inflamado enche de luz as praças, as ruas e as avenidas, escalda o tecto das casas, queima a pele das pessoas. O que sabe bem então é entrar numa cervejaria, pedir um fino e bebê-lo quase de um trago, pedir outro, e outro, e outro, para conseguir acalmar a sede que apera a garganta. Desde muito cedo, o que apetece também é refrescar o corpo no ar condicionado que toma conta do ambiente.

Quem vem do planalto e se habituou a temperaturas amenas incomoda-se com a canícula diária. A roupa cola-se ao corpo, o suor cai em bagas das axilas e do rosto, nenhuma árvore dos passeios públicos dá sombra suficiente para o peão recuperar fôlego. (p. 277).

Lemos aqui a impressão positiva e saudosa do cenário angolano. O calor, o suor, aliviados pelo "civilizado" ar condicionado e a sede aplacada com a cerveja. Apreciar as modernidades introduzidas pelo colonizador levanta a questão da não radicalidade do ódio nutrido pelo colonizador por parte do colonizado. Apreciar os benefícios de outra forma de vida mais fácil, menos penosa, é atitude louvável pois revela a abertura para o novo. O grande óbice é, justamente, o desrespeito e a subalternização do naturais da terra, seus legítimos donos.

As personagens de Inácio Rebelo de Andrade, mais especificamente de O pecado maior de Abel, Saudades do Huambo, Na babugem do êxodo e Passageiro sem bilhete, mostram como o exílio foi um processo involuntário, ditado por razões diferentes, como descreve Mario Benedetti em relação ao exílio na América Latina.

Quando, a mediado de los años setenta comenzó la ola de emigración política y massiva, la decisión de abandonar el país próprio tenia la coherencia de ser virtualmente ajena ao indivíduo, ya que no era éste quien resolvia espontáneamente incorporarse a la diáspora; el impulso directo o indirecto venía casi siempre de la represión. Se emigraba por varías razones, pero, sobre todo, para evitar la prisión y la tortura y, em definitiva, para salvar la vida. Hoy día es previsible que a medida que la situación se vaya normalizando em la comarca del terror, a medida que vayan verdadeiramente desaparecendo los riesgos y las amenazas, el desexílio pasará a ser uma decisión individual. Cada exiliado deberá resolver por sí mismo si regressa a su tierra o se queda em el país de refugio. (p.40).

Na África, como na América Latina, a impossibilidade de permanecer na pátria, com seus riscos e ameaças, forçaram um exílio não ditado pela vontade do cidadão, levando-o a um porto distante, um lugar novo para tentar replantar suas raízes. Sebastião, personagem de 
Na babugem, a perda dos pais e a rejeição dos tios conduziram a outras terras. Duplamente espoliado no seu patrimônio afetivo, o rapaz decidiu adotar a África como o seu Eldorado. Ali trabalhou e enriqueceu. Constituiu família e sentiu-se em lugar seu. De repente, a insegurança do regime, as sangrentas lutas entre colonizador e colonizado reabriram a cicatrizada ferida do primeiro exílio. Um novo se impôs ao comerciante, homem feito, adaptado à nova pátria. A necessidade do desexílio (para usar a expressão de Mario Benedetti) não foi ditada pela vontade do personagem como não o foi da primeira vez. Sebastião não se sentiu partindo para realizar o desexílio. Ao contrário, sentiu-se duplamente exilado e insatisfeito.

Essa temática, também abordada por Edward Said, admite que o exilado sabe que, num mundo secular e contingente, as pátrias são sempre provisórias. Fronteiras e barreiras que nos fecham na segurança de um território familiar também podem se tornar prisões e são, com frequência, defendidas para além da razão e da necessidade. O exilado atravessa fronteiras, rompe barreiras do pensamento, da experiência (2001: 58).

Foi como prisioneiro que Sebastião aterrissou no aeroporto da Portela de Sacavém, juntando-se a levas de retornados. Não tinha mais casa, amigos, bens. A fortuna que amealhou nos anos de trabalho em Angola ficou no Huambo. O pouco dinheiro que conseguiu trazer, adquiriu-o com um agiota. O destino seria ir para um abrigo do governo e receber a "esmola". Revoltado, tentou resistir mas convenceu-se do caráter definitivo daquele exílio. Alquebrado, sofrido, assistiu ao internamento de seu filho Pedro num asilo para perturbados mentais. Os dias na pensão do Areeiro(bairro de Lisboa) foram parcos já que não havia dinheiro para pagar. Submeter-se à caridade dos "traidores" representou o último degrau de uma dignidade pisada, da identidade destroçada.

Observa-se, na narrativa, a pluralidade de significados que assinalam não só as vivências, como também a condição de forasteiros, inadaptados, depressivos. A sensação de estrangeiro gera o desconforto típico de quem é arrancado de suas raízes para tentar replantá-las em outro espaço geográfico. $\mathrm{O}$ autor, pela sua própria biografia, vivendo entre duas culturas, foi bastante hábil para configurar personagens exiladas.

Lesado no seu patrimônio afetivo, além do material, o autor revela o sentimento profundo de perda nas palavras de Abel, personagem do seu livro:

[...] bastante pior do que todas essas faltas graves - fora roubar-lhe( o verbo era forte, mas não havia outro mais adequado), fora roubar-lhe as referências e deixa-lo naquela procura recorrente da identidade. Como que no meio de uma encruzilhada de caminhos sem tabuletas de destino [...]" (O pecado maior de Abel, p. 305-306).

Não poderia sentir de outro modo o confisco das raízes, da confortável sensação de pertencimento, o escritor Inácio Rebelo de Andrade. Ao partir com sua família para o Portugal sem perspectiva de retorno, revelou-se incompreensível, posto que era, em Angola, um cidadão engajado, filiado ao partido em defesa da independência, um exaltado militante, pronto a construir uma pátria independente. A mácula, a grande e extensa nódoa era, ironicamente, a cor da sua pele. Nascido e criado em Angola: "Era branco, mas isso não passava de uma contingência biológica, devida a factores de natureza genética, não de identidade nacional. Foi por pensar precisamente assim que se filiou ao MPLA" (Passageiro sem bilhete, pp. 31 e 32). 
Saber-se rejeitado pelo seu povo entristeceu-o e trouxe-lhe o sentimento da orfandade. Se não era angolano, o que seria, afinal?

Um exilado. Estrangeiro na terra onde não repousavam seus familiares no último sono. Pior: sem perspectivas de retorno, sonho acalentado durante a vida inteira. A dolorosa experiência no exílio, adiando sempre a realização do longínquo sonho de voltar, apontou a escrita como único caminho de volta. Não à pátria que é, hoje, mudada, abrigando outros ideais. Retorno, sim à memória da pátria-mãe, fixada no recôndito do ser que ainda pranteia a passagem irremediável do tempo.

Nas palavras exemplares de Fernando Pessoa (1888-1935), através de seu semi-heterônimo Bernardo Soares, pode-se entender melhor a problemática daqueles que se sentem nostálgicos com a perda da raiz/rizoma natal. A frase “minha pátria é a língua portuguesa” poderia ser lida como a forma particular que Fernando Pessoa tinha de entender a pátria: desenraizado ainda criança, o poeta deixou o cenário da terra natal, adotando uma nova geografia (Durban, África) e até falando e escrevendo em uma segunda língua, o inglês.

Ausente do país, é por meio da posse de outro objeto amado - a linguagem - que o indivíduo se relaciona com o mundo. Parece ser essa a problemática que está por trás da palavra exílio, duplamente entendida como a impossibilidade de voltar ao ponto de origem, a não ser pela memória (caso dos emigrados de países tomados por convulsões ou regimes totalitaristas ou, ainda, dos exilados políticos por opção própria) ou pela manutenção da língua materna como idioma de expressão afetiva, mesmo que se fale/escreva em uma outra língua majoritária.

Nesse sentido, a literatura de um Kafka, tal como explicitada por Deleuze e Guattari (Kafka por uma literatura menor), ilustraria o que o filósofo chama de tentativa de reterritorialização/ desterritorialização: a capacidade de articular-se em uma língua que não é a sua, fazendo-a vibrar com intensidade sob o ângulo que sua visão de estrangeiro permite e enriquecendo-a com usos simbólicos ou utilizando essa linguagem com sobriedade.

Esse sentimento de nostalgia experimentado por artistas em geral, em relação simultânea com a língua e a pátria, parece obter a cura mediante a criação artística. Quanto mais distante dessas referências fundamentais, mais o autor procura superar esse exílio por meio do desabafo na expressão artística.

A sensação de desenraizamento é fundada num certo desejo: o de exprimir para si e para os outros, o de se deixar falar por uma língua que já não é a sua, constatando-se quão distante se está dela e, paradoxalmente, tão perto, uma vez que esta não foi nunca esquecida. Esse movimento de busca tem um caráter circular, pois, por mais voltas que o homem dê, encontrará sempre a imagem da pátria a acenar-lhe com o convite da volta.

A obra de Inácio Rebelo de Andrade também pode ser enquadrada na perspectiva do exilado. Seus personagens experimentam o drama do ser de fora, vivendo uma dicotomia que de um lado apela para as referências culturais de Angola e, por outro, sofrem a influência cultural, ideológica e psíquica da pátria no exílio, criando um movimento de báscula em que pesa mais o prato que contém a memória da pátria-além.

A experiência do exílio é vivida como culpa, o que faz, a personagem se auto-recriminar e registrar sua tristeza como culpa por estar desertando do mundo onde haviam nascido e morrido seus ancestrais.

A solidão, pórtico para recordações de um mundo que foi e já não é mais. 
Mesmo próximo de alguns amigos e compatriotas e até mesmo ao lado da família, o exilado é um forasteiro solitário que guarda viva no peito a imagem da pátria. O exercício simples de rememoração vai-se tornando uma espécie de mal secreto cuja revelação só pode ser feita aos que compartilham a mesma dor. Encontrar alguém para falar da pátria faz com que as cores da lembrança percam o tom esfumado e readquiram o colorido da antiga pátria.

O texto de Inácio, tão marcado por referências de culpa, também liga o sentimento da culpabilidade à evidência de que abandonar as raízes é marca que se leva a qualquer lugar. Com o argumento fundamentado na ideia de que o exilado sai não apenas da pátria, mas com ela, pela impossibilidade de recuperá-la.

A saudade da terra de origem, o desejo permanente de estar dentro e fora da pátria, ubiquidade impossível, articulados à ideia de desenraizamento e sentimento de estranheza, são referências constantes na maioria dos textos de autores africanos que vivenciaram o exílio.

É mister reconhecer, na obra de Inácio Rebelo de Andrade, um contributo de inegável valor para as literaturas lusófonas. Seu texto dialoga com a melhor ficção contemporânea, pela atualidade dos temas, pela leveza e propriedade com que utiliza a linguagem. Sua incursão pela prosa não representa um mero exercício literário, mas a realização plena de um projeto que se consolida a cada obra, apontando para questões eternas e universais do ser humano como o exílio.

\section{Referências bibliográficas:}

Andrade, I. R. de. (1998). Quando o Huambo era Nova Lisboa: Lisboa: Vega.

-. (2004). Na babugem do êxodo. Lisboa: Vega. . (2005). O pecado maior de Abel. Lisboa: Vega.

Benedetti, M. (1985). El Desexilio y otras conjeturas. Buenos Aires: Editorial Nueva Imagen S.R.L.

Deleuze, G., \& Guatari, F. (2014). Kafka: por uma literatura menor. Belo Horizonte: Autêntica Editora.

Kristeva, J. (1991). Estrangeiros para nós mesmos. Rio de Janeiro: Rocco.

Mosès, S. (1982). Système et revelation: la philosophie de Franz Rosenweig. Paris: Seuil.

Wilson, C. (1985). O Outsider: o Drama Moderno da Alienação e da Criação. São Paulo: Martins Fontes.

Said, E. (2001). Reflexões sobre o exílio e outros ensaios. São Paulo: Companhia das Letras. 